\title{
EVALUASI KINERJA KONSULTAN PENGAWAS PADA PROYEK PEMBANGUNAN JALAN DI PROVINSI KALIMANTAN TIMUR
}

\author{
Amir \\ Dosen Program Studi Teknik Sipil Fakultas Teknik \\ Universitas 17 Agustus 1945 Samarinda, \\ E-mail: B277mir@gmail.com / HP. 08125517799
}

\begin{abstract}
ABSTRAK
Pembangunan jalan diprovinsi Kalimantan timur yang dibangun pada tahun anggaran 2015 diharapkan dapat menghasilkan infrastruktur jalan yang sesuai dengan yang direncanakan, dan semua itu tentunya tidak bisa terlepas juga dari peran serta kinerja dari konsultan pengawas yang memberikan layanan keahlian kepada Owner. Tujuan penelitian adalah untuk mengetahui konsultan pengawas pada proyek pembangunan jalan di provinsi Kalimantan timur dan tujuan untuk mendapatkan faktor yang paling dominan mempengaruhinya serta menentukan strategi untuk meningkatkan kinerja konsultan pengawas pada proyek pembangunan jalan. Metodologi analisis data yang digunakan adalah analisis faktor dan analisis regresi linier berganda terhadap jawaban dari kuisioner yang disebarkan kepada 55 responden dari pihak kontraktor dan Owner yang terlibat dalam proyek pembangunan jalan di provinsi Kalimantan Timur. Berdasarkan hasil penelitian, kinerja konsultan pengawas secara signifikan pada proyek pembangunan jalan di provinsi Kalimantan timur adalah faktor kemampuan manajemen pengawasan penyelenggaraan proyek dengan nilai koefisen $t_{\text {hitung }}=2,575>t_{\text {tabel }}=$ 1,679 dan faktor kehadiran kerja dengan nilai koefisen $t_{\text {hitung }}=2,317>t_{\text {tabel }}=1,679$. Faktor yang paling dominan mempengaruhi kinerja konsultan pengawas pada proyek pembangunan jalan diprovinsi Kalimantan timur adalah faktor kemampuan manajemen pengawasan penyelenggaraan proyek dengan nilai Koefisien Koefisien $\beta$ sebesar 0,639. Strategi yang harus dilakukan untuk meningkatkan kinerja konsultan pengawas pada proyek jalan adalah konsultan pengawas wajib mengikuti pelatihan intensif (workshop) serta mengadakan rapat diawal kegiatan tentang evaluasi dan pembahasan spesifikasi teknis terkait dengan kondisi permasalahan dilapangan dan khusus item pekerjaan di RAB kontrak, konsultan pengawas wajib mengikuti pelatihan intensif (workshop) serta mengadakan rapat diawal kegiatan tentang evaluasi dan pembahasan tentang tanggung jawab serta SOP sebagai konsultan pengawas, konsultan pengawas wajib mengikuti pelatihan intensif (workshop) serta mengadakan rapat diawal kegiatan tentang evaluasi dan pembahasan permasalahan dokumen kontrak serta kelengkapankelengkapan kontrak fisik, konsultan pengawas wajib mengikuti pelatihan intensif (workshop) serta mengadakan rapat diawal kegiatan tentang pembahasan keselamatan kerja terkait dengan kondisi permasalahan dilapangan dan khusus item pekerjaan di $\mathrm{RAB}$ kontrak serta tata acara pengajuan keselamatan kerja sebelum bekerja.
\end{abstract}

Kata Kunci: Faktor kinerja, Konsultan Pengawas 


\begin{abstract}
Road development in the province of East Kalimantan which was built in the 2015 fiscal year is expected to produce road infrastructure as planned, and of course all this cannot be separated from the role and performance of the supervisory consultants who provide expertise services to the Owner. Therefore, this study was conducted to determine the supervisory consultant on road construction projects in East Kalimantan province and the objective of obtaining the most dominant factors influencing it and determining strategies to improve the performance of supervisory consultants on road construction projects. The data analysis methodology used is factor analysis and multiple linear regression analysis on the answers to the questionnaire distributed to 55 respondents from contractors and owners involved in road construction projects in East Kalimantan Province. Based on the research results, the performance of the supervisory consultant significantly on road construction projects in the province of East Kalimantan is the factor of the management capability of the project implementation supervision with a coefficient of tcount $=2.575>$ ttable $=1.679$ and $a$ work attendance factor with $a$ coefficient value of tcount $=2.317>$ ttable $=1.679$. The most dominant factor influencing the performance of the supervisory consultant on road construction projects in the province of East Kalimantan is the management capacity factor for project implementation supervision with a coefficient of 0.639. The strategy that must be taken to improve the performance of the supervisory consultant on road projects is that the supervisory consultant is required to attend intensive training (workshops) and hold a meeting at the beginning of the activity regarding evaluation and discussion of technical specifications related to the condition of problems in the field and specifically the work items in the RAB contract, the supervisory consultant is obliged to attend intensive training (workshops) and holding meetings at the beginning of the activity regarding evaluation and discussion of responsibilities as well as SOPs as a supervisory consultant, the supervisory consultant is obliged to attend intensive training (workshops) and hold a meeting at the beginning of the activity regarding evaluation and discussion of contract document issues and completeness of physical contracts, the supervisory consultant must attend intensive training (workshops) and hold a meeting at the beginning of the activity on discussing work safety related to the condition of problems in the field and specifically the work items in the contract $R A B$ and procedures submission of work safety before work.
\end{abstract}

Keywords: Performance Factor, Supervisory Consultant

\title{
PENDAHULUAN
}

Pembangunan prasarana infrastruktur di Propinsi Kalimantan Timur merupakan urat nadi perekonomian yang merupakan sektor lainnya. Selain itu prasarana bidang kebinamargaan memiliki peranan yang sangat penting untuk menghubungan antara kota, kawasan produksi dengan daerah pemasaran dan pusat-pusat pertumbuhan lainnya. Prasarana infrastruktur bidang kebinamargaan merupakan prasarana yang sangat penting untuk mempelancar kegiatan perekonomian. Makin meningkatnya usaha pembangunan menuntut pula peningkatan pembangunan infrastruktur pendukungnya guna memudahkan mobilitas penduduk dan mempelancar arus lalu lintas barang dari suatu daerah ke daerah lain. 
Kegiatan pembangunan jalan di Propinsi Kalimantan Timur yang dibangun pada tahun 2015 diharapkan dapat menghasilkan pembangunan yang sesuai dengan yang direncanakan tepat waktu, tepat mutu dan tepat biaya, dan semua itu tentunya tidak bisa terlepas juga dari peran serta kinerja dari owner, kontraktor serta konsultan pengawas. Owner dalam hal ini adalah kuasa pengguna anggaran (KPA) serta menunjuk pejabat pelaksana teknis kegiatan (PPTK) pekerjaan fisik yang diberi wewenang mewakili KPA untuk mengendalikan pekerjaan kontraktor. PPTK pekerjaan fisik dibantu oleh tim teknis konsultan pengawas yang ditunjuk oleh direksi bagian pengawasan yang secara operasional melaksanakan tugas sehari-hari dalam mengawasi pekerjaan kontraktor dan keberadaannya diatur dalam kontrak pengawasan itu sendiri. Namun di dalam pelaksanaannya banyak konsultan pengawas tersebut yang belum menjalankan peran serta kinerja dengan pengawasan yang baik.

Dalam rangka meningkatkan profesionalisme jajaran konsultan pengawas tentunya penanganannya tidak dapat dilakukan secara persial, namun proses ini menuntut pembenahan secara menyeluruh. Upaya peningkatan tersebut harus didasarkan pada visi, misi dan strategi yang tepat. Oleh karena itu pemantauan terhadap kinerja konsultan pengawas menjadi sangat penting.

Adapun kinerja konsultan pengawas pada kegiatan pembangunan jalan provinsi di Kalimantan timur adalah kemampuan manajemen pengawasan penyelenggaraan kegiatan, pengendalian mutu pekerjaan segi kualitas dan kuantitas, pengendalian volume dan biaya, pengedalian waktu, koordinasi Penyiapan materi rapat pelaksanaan, penguasaan/pemahaman tugas-tugas dan kewajiban yang tercantum dalam KAK, ketepatan, kecepatan dan kelengkapan dalam menyampaikan laporan, kehadiran kerja. Kinerja kemampuan manajemen pengawasan diatas didapat berdasarkan rapat evaluasi yang dimonitoring oleh konsultan core tiem terhadap konsultan-konsultan di lingkungan dinas bina marga pekerjaan umum provinsi Kalimantan timur. Penelitian ini bertujuan untuk menganalisis faktor-faktor yang mempengaruhi kinerja konsultan pengawas pada proyek pembangunan jalan di Provinsi Kalimantan Timur, menganalisis faktor yang paling dominan mempengaruhi kinerja konsultan pengawas pada proyek pembangunan jalan di Provinsi Kalimantan Timur dan menentukan strategi yang harus dilakukan untuk meningkatkan kinerja konsultan pengawas pada proyek pembangunan jalan di Provinsi Kalimantan Timur.

\section{TINJAUAN PUSTAKA}

\section{Proyek Konstruksi}

Proyek adalah kegiatan sekali lewat, dengan waktu dan sumber daya terbatas untuk mencapai hasil akhir yang telah ditentukan, misalnya produk atau fasilitas produksi. Kegiatan proyek dapat diartikan sebagai satu kegiatan sementara yang berlangsung dalam jangka waktu terbatas, dengan alokasi sumber daya tertentu dan dimaksudkan untuk menghasilkan produk atau devirable yang kriteria mutunya telah digariskan dengan jelas (Suharto,2001). Mengenai konstruksi, Barrie and Pulson (1984) menyampaikan bahwa konstruksi merupakan suatu proses dimana rencana dan spesifikasi para perancang dikonversikan menjadi struktur dan fasilitas fisik 


\section{Pengertian Pengawasan}

Pengawasan adalah merupakan pemeriksaan terhadap penggunaan tata laksana yang berlaku dalam pelaksanaan tugas agar terhindar dari penyimpangannya. Pengertian lain dari pengawasan adalah usaha mengevaluasi data/fakta proyek, dengan disertai kewenangan menjalankan SOP memberikan Petunjuk untuk tindakan turun tangan (PT3).

\section{Pengertian Kinerja}

Kinerja adalah penentuan cara periodik operasional organisasi, bagian organisasi dan karyawannya berdasarkan standar dan kriteria yang telah ditetapkan sebelumnya (Purnomo, 2008).

\section{METODOLOGI PENELITIAN}

\section{Jenis dan Sumber Data}

Penelitian ini menggunakan metode survei dengan cara menjaring pendapat, pengalaman dan sikap responden mengenai masalah-masalah yang ada, dengan mengambil data primer melalui kuisioner dan data sekunder dari institusi yang terkait. Berdasarkan faktor-faktor yang mempengaruhi kinerja konsultan pengawas pada proyek pembangunan jalan di provinsi Kalimantan timur, maka ditentukan faktor-faktor yang dilanjutkan dengan menentukan variabel - variabel untuk dijadikan butir - butir pertanyaan yang akan diukur dalam bentuk kuisioner.

Data primer yaitu data yang diperoleh secara langsung dalam hal ini dengan melakukan survey lapangan yang menggunakan metode pengumpulan data original lewat pembagian kuesioner; dan data sekunder, yaitu data yang diambil dari perusahaan berupa dokumen, catatan, laporan-laporan, hasil-hasil penelitian, bukubuku, artikel dan berbagi publikasi serta instansi terkait yang relevan dengan masalah yang diangkat.

\section{Metode Analisis}

Analisis data menggunakan analisis regresi berganda dengan bantuan software SSPS dengan empat tahap, Tahap pertama, pengujian kualitas data, melalui uji Validitas dan Reliabilitas. Tahap kedua, melakukan uji penyimpangan asumsi klasik, melalui uji asumsi klasik (Normalitas, Non-Multikolinieritas, Homoskedastisitas, Non-Autokorelasi). Tahap ketiga, melakukan analisis regresi. Dan tahap keempat, melakukan uji hipotesis (Uji t dan Uji F). Analisis Regresi Berganda Untuk mencapai tujuan penelitian maka digunakan metode analisis regresi linear berganda. Menurut Sugiyono (2007), regresi linear berganda dilakukan untuk meramalkan bagaimana keadaan (naik turunnya) variabel dependen (kritarium), bila dua atau lebih variabel independent sebagai faktor prediktor dimanipulasi (dinaik-turunkan nilainya) jadi analisis regresi linear barganda akan dilakukan bila jumlah variabel independennya minimal 2. Formula yang digunakan adalah $Y=a+b_{1} X_{1}+b_{2} X_{2+} b_{3} X_{3} \cdots \cdots \cdots \cdots+b_{n} X_{n}$

Koefisien Korelasi (R) dan determinasi (R2) Uji determinan (R2) pada intinya mengukur seberapa jauh kemampuan model dalam menerangkan variasi variabel depeden. Nilai koefisien determinasi adalah antar nol dan satu. Nilai R2 yang kecil berarti kemampuan variabel-variabel independen dalam menjelaskan variasi variabel dependen amat terbatas. Nilai yang mendekati satu berarti variabel- 
variabel independen memberikan hampir semua informasi yang dibutuhkan untuk memprediksi variasi variabel dependen.

\section{HASIL PENELITIAN DAN PEMBAHASAN}

\section{Analisis Regresi Berganda}

Tabel 1. Uji asumsi Normalitas

\begin{tabular}{|l|c|c|}
\hline \multicolumn{1}{|c|}{ Statistik Uji } & Nilai & Keterangan \\
\cline { 1 - 2 } Kolmogorov-Smirnov Z & 0,556 & \multirow{2}{*}{ Menyebar normal } \\
\cline { 1 - 2 }$p$-value & 0,917 & \\
\hline
\end{tabular}

Sumber: Hasil Analisis SPSS

Tabel 2. Uji asumsi Non Multikolinieritas

\begin{tabular}{|c|c|c|}
\hline Variabel Independen & VIF & Keterangan \\
\hline $\begin{array}{l}\text { Kemampuan manajemen pengawasan } \\
\text { penyelenggaraan proyek (X1) }\end{array}$ & 3,416 & Non Multikolinieritas \\
\hline $\begin{array}{l}\text { Pengendalian mutu pekerjaan segi kualitas dan } \\
\text { kuantitas (X2) }\end{array}$ & 3,684 & Non Multikolinieritas \\
\hline Pengendalian volume dan biaya (X3) & 2,670 & Non Multikolinieritas \\
\hline Pengedalian waktu (X4) & 2,001 & Non Multikolinieritas \\
\hline $\begin{array}{l}\text { Koordinasi penyiapan materi rapat pelaksanaan } \\
\text { (X5) }\end{array}$ & 1,154 & Non Multikolinieritas \\
\hline $\begin{array}{l}\text { Penguasaan/pemahaman tugas-tugas dan } \\
\text { kewajiban yang tercantum dalam KAK (X6) }\end{array}$ & 2,498 & Non Multikolinieritas \\
\hline $\begin{array}{l}\text { Ketepatan, kecepatan dan kelengkapan dalam } \\
\text { menyampaikan laporan (X7) }\end{array}$ & 1,109 & Non Multikolinieritas \\
\hline Kehadiran kerja (X8) & 3,724 & Non Multikolinieritas \\
\hline
\end{tabular}

Sumber: Hasil Analisis SPSS

Tabel 3. Uji asumsi Homoskedastisitas

\begin{tabular}{|l|c|c|}
\hline \multicolumn{1}{|c|}{ Statistik Uji } & Nilai & Keterangan \\
\cline { 1 - 2 } Korelasi Rank Spearman & 0,000 & \multirow{2}{*}{ Homoskedastisitas } \\
\cline { 1 - 2 } p-value & 1,000 & \\
\hline
\end{tabular}

Sumber: Hasil Analisis SPSS

Tabel 4. Uji asumsi Non-Autokorelasi

Model Summary(b)

\begin{tabular}{|l|l|r|r|r|r|}
\hline Model & R & R Square & $\begin{array}{c}\text { Adjusted R } \\
\text { Square }\end{array}$ & $\begin{array}{c}\text { Std. Error of } \\
\text { the Estimate }\end{array}$ & Durbin-Watson \\
\hline 1 &, $684(\mathrm{a})$ &, 468 &, 375 &, 82872 & 1,911 \\
\hline
\end{tabular}

a Predictors: (Constant), X8, X3, X5, X7, X4, X6, X1, X2

b Dependent Variable: $Y$

Sumber: Hasil Analisis SPSS 
Tabel 5. Ringkasan Hasil Analisis Regresi

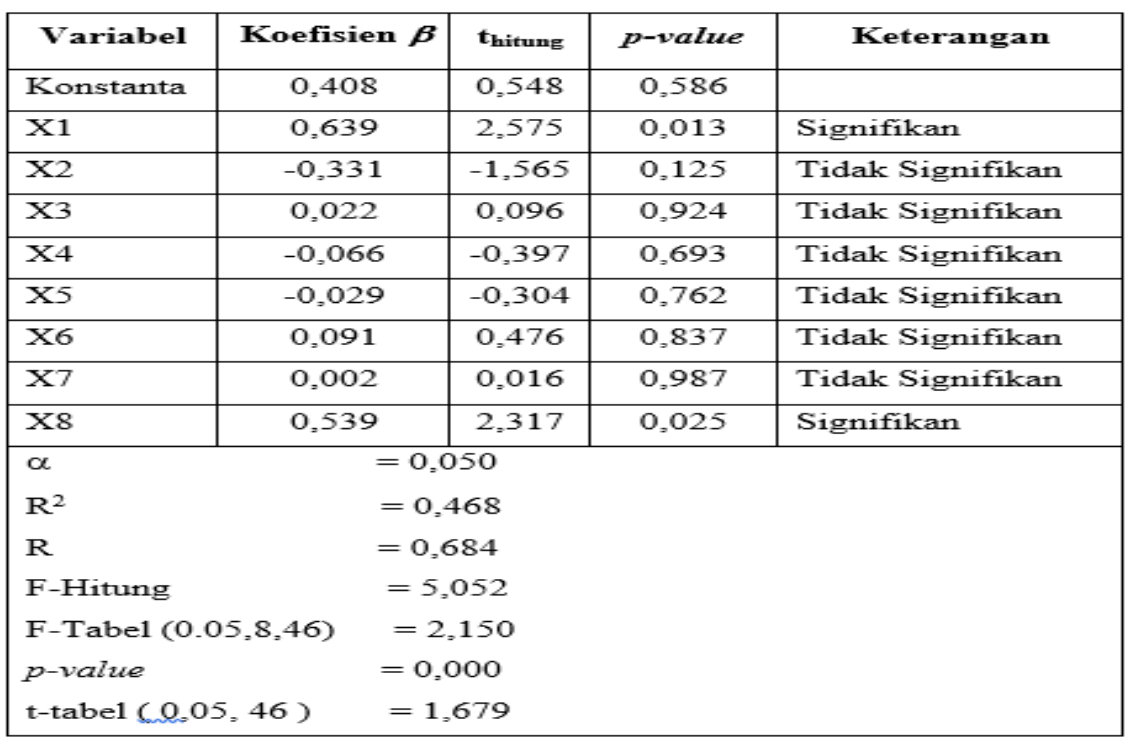

Berdasarkan hasil analisis pada Tabel 5 menunjukkan bahwa variabel independen memiliki nilai yang signifikan (berpengaruh siginifikan terhadap kinerja konsultan pengawas proyek pembangunan jalan) yaitu variabel kemampuan manajemen pengawasan penyelenggaraan proyek (X1) dan variabel kehadiran kerja (X8). Sedangkan variabel lainnya tidak memberikan pengaruh yang signifikan terhadap kinerja konsultan pengawas proyek pembangunan jalan Interprestasi model regresi yang didapatkan berdasarkan Tabel 4.20 di atas adalah sebagai berikut:

$\mathrm{Y}=0,408+0,639 \mathrm{X} 1-0,331 \mathrm{X} 2+0,022 \mathrm{X} 3-0,066 \mathrm{X} 4-0,029 \mathrm{X} 5+0,091 \mathrm{X} 6+$ $0,002 \times 7+0,539 \times 8+\varepsilon$

Dimana:

Y : Kinerja Konsultan Pengawas

$\mathrm{X} 1$ : Variabel kemampuan manajemen pengawasan penyelenggaraan proyek

$\mathrm{X} 2$ : Variabel pengendalian mutu pekerjaan segi kualitas dan kuantitas

$\mathrm{X} 3$ : Variabel pengendalian volume dan biaya

$\mathrm{X} 4$ : Variabel pengedalian waktu

$\mathrm{X} 5$ : Variabel koordinasi penyiapan materi rapat pelaksanaan

X6 : Varaibel penguasaan/pemahaman tugas-tugas dan kewajiban yang tercantum dalam KAK

X7 : Variabel ketepatan, kecepatan dan kelengkapan dalam menyampaikan laporan

X8 : Variabel kehadiran kerja

\section{Faktor-faktor yang Dominan}

Berdasarkan Tabel 5 menunjukkan bahwa variabel kemampuan manajemen pengawasan penyelenggaraan proyek adalah variabel yang memiliki nilai koefisien $\beta(0,639)$ yang paling besar diantara nilai yang signifikan itu berarti pada penelitian ini, variabel yang paling dominan pengaruhnya terhadap kinerja konsultan pengawas pada proyek pembangunan jalan adalah variabel kemampuan manajemen pengawasan penyelenggaraan proyek, artinya kinerja konsultan pengawas banyak dipengaruhi oleh variabel kemampuan manajemen pengawasan penyelenggaraan proyek. Nilai Koefisien $\beta$ yang positif 
mengindikasikan bahwa semakin baik variabel kemampuan manajemen pengawasan penyelenggaraan proyek maka kemungkinan besar kinerja konsultan pengawas pada proyek pembangunan jalan akan semakin baik dan proyek tersebut dapat diselesaikan sesuai dengan baik.

\section{Strategi}

Strategi yang harus dilakukan untuk meningkatkan kinerja konsultan pengawas terhadap waktu pelaksanaan adalah sebagai berikut :

1. Konsultan pengawas wajib mengikuti pelatihan intensif (workshop) serta mengadakan rapat diawal kegiatan tentang evaluasi dan pembahasan spesifikasi teknis terkait dengan kondisi permasalahan dilapangan dan khusus item pekerjaan di RAB kontrak.

2. Konsultan pengawas wajib mengikuti pelatihan intensif (workshop) serta mengadakan rapat diawal kegiatan tentang evaluasi dan pembahasan tentang tanggung jawab serta SOP sebagai konsultan pengawas.

3. Konsultan pengawas wajib mengikuti pelatihan intensif (workshop) serta mengadakan rapat diawal kegiatan tentang evaluasi dan pembahasan permasalahan dokumen kontrak serta kelengkapan-kelengkapan kontrak fisik.

4. Konsultan pengawas wajib mengikuti pelatihan intensif (workshop) serta mengadakan rapat diawal kegiatan tentang pembahasan keselamatan kerja terkait dengan kondisi permasalahan dilapangan dan khusus item pekerjaan di RAB kontrak serta tata acara pengajuan keselamatan kerja sebelum bekerja.

5. Konsultan pengawas wajib mengikuti pelatihan intensif (workshop) serta mengadakan rapat diawal kegiatan tentang evaluasi dan pembahasan kehadiran kerja pengawas di setiap tahapan pekerjaan serta sistem absensi kerja dilapangan nantinya.

6. Konsultan pengawas wajib mengikuti pelatihan intensif (workshop) serta mengadakan rapat diawal kegiatan tentang evaluasi dan pembahasan kehadiran kerja pengawas disetiap pengujian mutu hasil pekerjaan dan sistem absensi kerja di lapangan nantinya serta pemaparan kembali tentang metodologi dan program kerja pengawasan.

\section{PENUTUP}

\section{Kesimpulan}

Berdasarkan hasil penelitian dan pembahasan dapat diambil kesimpulan yaitu sebagai berikut :

1. Dari hasil uji F didapatkan bahwa faktor X1, X2, X3, X4, X5, X6, X7, dan X8 berpengaruh secara simultan terhadap kinerja konsultan pengawas proyek pembangunan jalan nilai $F_{\text {hitung }}=5,052>F_{\text {tabel }}=2,150$. Namun dari hasil Uji $t$ secara parsial faktor - faktor yang mempengaruhi kinerja konsultan pengawas secara signifikan terhadap proyek pembangunan jalan di provinsi Kalimantan timur adalah :

a. Faktor kemampuan manajemen pengawasan penyelenggaraan proyek dengan nilai koefisen $t_{\text {hitung }}=2,575>\mathrm{t}_{\text {tabel }}=1,679$.

b. Faktor Kehadiran kerja dengan nilai koefisen $t_{\text {hitung }}=2,317>t_{\text {tabel }}=1,679$. 
2. Faktor yang paling dominan mempengaruhi kinerja konsultan pengawas pada proyek pembangunan jalan di provinsi Kalimantan timur adalah faktor kemampuan manajemen pengawasan penyelenggaraan proyek dengan nilai Koefisien $\beta$ sebesar 0,639.

3. Strategi yang harus dilakukan untuk meningkatkan kinerja konsultan pengawas terhadap waktu pelaksanaan adalah sebagai berikut :

a. Konsultan pengawas wajib mengikuti pelatihan intensif (workshop) serta mengadakan rapat diawal kegiatan tentang evaluasi dan pembahasan spesifikasi teknis terkait dengan kondisi permasalahan dilapangan dan khusus item pekerjaan di RAB kontrak.

b. Konsultan pengawas wajib mengikuti pelatihan intensif (workshop) serta mengadakan rapat diawal kegiatan tentang evaluasi dan pembahasan tentang tanggung jawab serta SOP sebagai konsultan pengawas.

c. Konsultan pengawas wajib mengikuti pelatihan intensif (workshop) serta mengadakan rapat diawal kegiatan tentang evaluasi dan pembahasan permasalahan dokumen kontrak serta kelengkapan-kelengkapan kontrak fisik.

d. Konsultan pengawas wajib mengikuti pelatihan intensif (workshop) serta mengadakan rapat diawal kegiatan tentang pembahasan keselamatan kerja terkait dengan kondisi permasalahan dilapangan dan khusus item pekerjaan di $\mathrm{RAB}$ kontrak serta tata acara pengajuan keselamatan kerja sebelum bekerja.

e. Konsultan pengawas wajib mengikuti pelatihan intensif (workshop) serta mengadakan rapat diawal kegiatan tentang evaluasi dan pembahasan kehadiran kerja pengawas di setiap tahapan pekerjaan serta sistem absensi kerja dilapangan nantinya.

f. Konsultan pengawas wajib mengikuti pelatihan intensif (workshop) serta mengadakan rapat diawal kegiatan tentang evaluasi dan pembahasan kehadiran kerja pengawas disetiap pengujian mutu hasil pekerjaan dan sistem absensi kerja di lapangan nantinya serta pemaparan kembali tentang metodologi dan program kerja pengawasan.

\section{Saran}

Berdasarkan penelitian, dikemukakan beberapa saran sebagai berikut :

1. Untuk meningkatkan kinerja konsultan pengawas proyek pembangunan jalan maka konsultan harus memiliki tenaga ahli yang profesional dalam menjalankan tugasnya di lapangan.

2. Konsultan harus menjalin komunikasi dengan baik dengan pelaksana dari kontraktor, sehingga dapat dicapai hasil pekerjaan yang baik.

3. Konsultan harus memberikan instruksi - instruksi serta petunjuk - petunjuk yang perlu kepada kontraktor dalam pelaksanaan pekerjaan agar benar - benar berlangsung sesuai dengan ketetapan - ketetapan kontrak.

4. Owner harus memberikan teguran kepada konsultan yang tidak menjalankan tugasnya dengan benar dan sesuai dengan ketetapan kontrak

5. Kontraktor harus memperhatikan dengan baik saran maupun instruksi instruksi yang diberikan konsultan.

6. Untuk penelitian selanjutnya diharapkan menambahkan variabel - variabel lain yang berhubungan dengan cara kerja konsultan guna menyempurnakan hasil penelitian. 
JURNAL KACAPURI

JURNAL KEILMUAN TEKNIK SIPIL

Volume 4 Nomor 1 Edisi Juni 2021

\section{DAFTAR PUSTAKA}

1. Aliman. (2000), Modul Ekonometrika Terapan, PAU Studi Ekonomi UGM. Yogyakarta.

2. Arikunto, S. (2006), Prosedur Penelitian, Edisi Revisi ke VI, Penerbit Rineka Cipta Jakarta.

3. Barrie S. Donald and J.R Paulson C. Boyd, (1984), Manajemen Konstruksi Profesional, Edisi II, Penerbit Erlangga, Jakarta.

4. Cooper, R. Donald dan Emory, C. William, (1999), Metode Penelitian Bisnis. Alih Bahasa: Soetjipto, W dan Wikarya, U. Penerbit Erlangga, Jakarta.

5. Dipohusodo I, (1995), Manajemen Proyek dan Konstruksi, Edisi ketujuh, Penerbit

6. Kanisius, Yogyakarta.

7. Djajan, Anton, (1986), Pengantar Metode Statistik, Jilid 1 dan 2, LP3ES, Jakarta.

8. Draper, N.R. dan H. Smith, (1992), Analisa Regresi Terapan Edisi Kedua, Gramedia Pustaka Utama, Jakarta.

9. Ervianto, W.I, (2003), Manajemen Proyek Konstruksi, Penerbit Andi, Jogjakarta.

10. Eko Sugiarto, (2015), Menyusun Proposal Penelitian Kuanlitatif Skripsi dan Tesis, Suaka Media Yogyakarta

11. Ghozali I, M.Com, Akt, (2006), Aplikasi Analisis Mutivariate Dengan Program SPSS, Badan Penerbit Universitas Diponegoro, Semarang.

12. Gujarati, D, (1995), Ekonometrika, Penerbit Erlangga, Jakarta.

13. Husein Umar, (2007), Metode Penelitian : Untuk Skripsi dan Tesis Bisnis, PT. Raja Grafindo Persada, Jakarta.

14. Henri Yunianto, (2015), Analisis faktor-faktor kinerja konsultan pengawas yang berpengaruh terhadap waktu dan mutu pekerjaan proyek peningkatan jalan di kabupaten probolinggo, Tesis ITN, Malang

15. Malhotra, N. K, (1996), Marketing Research an Applied Orientation, Prentice Hall International, London

16. Nugraha, P, I. Natan dan R. Sutjipto, (1985), Manajemen Proyek Konstruksi Jilid I dan II, Penerbit Kartika Yudha, Surabaya.

17. Peraturan Menteri Pekerjaan Umum, No.45/PRT/M/2007, Pedoman Teknis Pembangunan Gedung Negara.

18. Riduwan, (2005), Dasar - dasar Statistika, Alfabeta, Bandung.

19. Santoso, S. (2001), SPSS versi 10 Mengolah data Statistik secara Profesional, PT. Elex Media Komputindo, Jakarta.

20. Sukandar, (2012), Faktor-faktor yang mempengaruhi Kinerja Konsultan Pengawas terhadap waktu pelaksanaan Proyek pembangunan gedung di kota malang, Tesis ITN, Malang.

21. Singarimbun, Masri \& Sofian Effendi, (2006), Metode Penelitian Survai, LP3ES, Jakarta.

22. Soeharto, I, (2001), Manajemen Proyek Dari Konseptual Sampai Operasional, Erlangga, Jakarta.

23. Sugiyono, (2006), Statistika untuk Penelitian, CV. ALFABETA, Bandung.

24. Sugiono. (2015), Memahami Penelitian Kualitatif, Alfabeta Bandung

25. Taufiq Amir, (2014), Merancang Kuesioner, Kencana 